\title{
Strengthening collaborations at the public health system-academic interface: a call to action
}

\author{
Erica Di Ruggiero ${ }^{1}$ (D) Andrew Papadopoulos ${ }^{2} \cdot$ Malcolm Steinberg $^{3} \cdot$ Régis Blais $^{4} \cdot$ Natalie Frandsen $^{5}$. \\ James Valcour ${ }^{6} \cdot$ Greg Penney $^{7}$
}

Received: 12 August 2020 / Accepted: 15 October 2020 / Published online: 11 November 2020

(C) The Canadian Public Health Association 2020

\begin{abstract}
In Canada and globally, the COVID-19 pandemic has highlighted the importance of reliable and responsive public health systems. The pandemic has required decisive leadership and collaboration across all sectors of society informed by the best available evidence. In this commentary, we argue that in order to create a robust public health system equipped to address current and future public health challenges, we must prioritize and invest in stronger relationships between public health practice and academia. We briefly review key recommendations following the SARS outbreak, particularly those calling for stronger linkages between public health academia and practice settings in Canada. We then propose key actions for strengthening these linkages. Echoing other COVID-19-related calls, which request long-term reinvestment in public health education and training, we recommend the following actions: (1) Improve collaboration between education programs and public health agencies to address system needs (e.g., surge capacity) and persisting health inequities; (2) Fund a pan-Canadian public health training initiative that builds on a renewed set of public health competencies to address priority training needs (e.g., equity-oriented leadership); and (3) Prepare a cadre of certified public health leaders who can progress along public health career pathways, including those already in practice.
\end{abstract}

\section{Résumé}

Au Canada et ailleurs dans le monde, la pandémie de COVID-19 a montré qu'il est important d'avoir des systèmes de santé publique fiables et réactifs. La pandémie nécessite un leadership décisif et une collaboration entre tous les secteurs de la société, éclairés par les meilleures preuves disponibles. Dans ce commentaire, nous faisons valoir que pour créer un système de santé publique robuste capable de relever les défis actuels et futurs, il faut privilégier des liens plus forts entre les praticiens de la santé publique et les milieux universitaires et y consacrer les investissements nécessaires. Nous passons brièvement en revue les principales recommandations qui ont suivi la crise du SRAS, en particulier celles qui réclamaient le renforcement des liens entre les facultés de santé publique et les milieux de pratique au Canada. Nous proposons ensuite des mesures clés pour renforcer ces liens. Faisant écho à d'autres appels à l'action liés à la COVID-19, qui préconisent un réinvestissement à long terme dans l'enseignement et la formation en santé publique, nous recommandons les mesures suivantes: 1) Améliorer la collaboration entre

Erica Di Ruggiero

e.diruggiero@utoronto.ca

1 Social and Behavioural Health Sciences Division \& Institute of Health Policy, Management and Evaluation, Dalla Lana School of Public Health, University of Toronto, Health Sciences Building, 155 College Street, Suite 408, Toronto, ON M5T 3M7, Canada

2 Department of Population Medicine, University of Guelph, Population Medicine Building, Room 212, 50 Stone Rd E, Guelph, ON N1G 2W1, Canada

3 Public Health Programs, Faculty of Health Sciences, Simon Fraser University, Blusson Hall, Rm 11018, 8888 University Drive, Burnaby, BC V5A 1S6, Canada
4 School of Public Health, Université de Montréal, PO Box 6128, Station Centre-ville, Montreal, QC H3C 3J7, Canada

5 School of Public Health and Social Policy, University of Victoria, 3800 Finnerty Road, Victoria, BC V8W 2Y2, Canada

6 Division of Community Health and Humanities, Faculty of Medicine, Memorial University of Newfoundland, St. John's, NL A1B 3V6, Canada

Canadian Public Health Association, 404-1525 Carling Avenue, Ottawa, ON K1Z 8R9, Canada 
les programmes d'enseignement et les organismes de santé publique pour aborder les besoins des systèmes (p. ex. leur capacité d'appoint) et les inégalités persistantes en santé; 2) Financer une initiative pancanadienne de formation en santé publique qui s'appuie sur un ensemble renouvelé de compétences en santé publique pour répondre aux besoins prioritaires en matière de formation (p. ex. le leadership axé sur l'équité); et 3) Préparer un groupe de dirigeants de santé publique agréés pouvant progresser dans les carrières de la santé publique, y compris des personnes qui exercent déjà la profession.

Keywords COVID-19 $\cdot$ Public health $\cdot$ Academia $\cdot$ Training $\cdot$ Collaboration $\cdot$ Leadership $\cdot$ Equity

Mots-clés COVID-19 $\cdot$ santé publique $\cdot$ universités $\cdot$ formation $\cdot$ collaboration $\cdot$ leadership $\cdot$ équité

\section{Nimble public health systems require stronger relationships between public health practice and academia}

In Canada and globally, the COVID-19 pandemic has underscored the importance of reliable and responsive public health systems. Led by public health experts, response to the pandemic has required decisive leadership and collaboration across all sectors of society, including academia, informed by the best available albeit ever-changing evidence base. Finding ourselves in the midst of a global pandemic is not a surprise to many scholars and advocates who point to the political, economic and environmental structures that paved the way for this global outbreak. The prevailing neoliberal model of economic globalization has created a "world system of accumulation that is everywhere breaking down traditional boundaries between animal diseases and humans...., undermining progressive governments committed to public health....", and destroying the health of our planet (Kouddous 2020). Morbidity and mortality data have further revealed that COVID-19 is not the great equalizer-people living and working in conditions of vulnerability are at much greater risk of infection and poorer physical and mental health outcomes (Mein 2020). By not assessing and reporting on the existence of inequities, or tackling the systems of oppression against Black, Indigenous and people of colour (BIPOC), our interventions will remain temporary solutions at best (Timothy 2020; Santé Montréal 2020). This pandemic has not created these inequitable outcomes; rather, it has further exposed them, as well as a greater need for a robust public health infrastructure across Canada that can effectively attend to these inequities. It has also underscored the need to better train the next generation of public health professionals about racial and other social inequities, and climate change to name but a few topics.

Strengthening collaborations between academia and public health practice offers one possible avenue. In this commentary, we argue that in part, to create a robust public health system equipped to address current and future public health challenges, it is necessary to prioritize and invest in stronger relationships between public health practice and academia. In particular, this involves training and research that focus on enhancing knowledge and competencies in existing and emerging areas relevant to public health practice, including health equity.

Collaborations are only as strong as their weakest link. A strong Canadian public health system able to lead and collaborate on interventions that stretch upstream to tackle the structural determinants of health and health equity is more critical than ever. Yet the COVID-19 pandemic has laid bare our system's fragility. Emerging gaps identified in the Canadian public health system include: the availability of quality and timely data to make informed decisions and account for differential risks of transmission; regionally variable levels of preparedness and of surge capacity, meaning the system's ability to respond to sudden increases in demand for services (e.g., testing capacity); and regionally variable levels of health workforce distribution and skills (Mishra et al. 2020). The pandemic has also highlighted the impacts of previous reductions in public health expenditures (Guyon and Perreault 2016). Nevertheless, expectations of an effective public health response to this pandemic persist, with no immediate plans to enhance current resources much less restore previous levels of investment. The situation is now being further exacerbated by uncertain financial outlooks and projections post-COVID-19. The pandemic has also demonstrated that effective collaboration across sectors beyond health and including academia is critical, especially in times of crisis.

Canada responded promptly with short-term health (e.g., physical distancing) and economic measures (e.g., expansions in available employment insurance; financial support for those without paid sick leave who are sick, quarantined or forced to stay home to fulfil caregiver duties; increased wages for essential workers and students) (Canadian Centre for Policy Alternatives 2020; Institute for Gender and the Economy \& YWCA Canada 2020). While important, these government commitments have not, so far, addressed funding of the public health system or the education of its public health workforce. Academic institutions also quickly pivoted to deliver their curriculum online and reorient research efforts toward COVID-19, stimulated by need and available funding. Given these immediate needs and challenges, there has been 
insufficient attention and efforts directed toward (re)building public health education and system capacity in Canada.

We argue that the ongoing rationing of Canadian public health expenditures coupled with the observed reduction in pan-Canadian leadership and support for public health education and training threaten the foundation and functioning of an effective public health system. We first briefly review selected recommendations following the SARS outbreak, particularly those calling for stronger linkages between public health academia and practice settings in Canada. We then propose key actions for strengthening these linkages.

\section{SARS should have better prepared us for the COVID-19 pandemic}

It is important to emphasize that we have been here before. A number of reports and recommendations were produced following the SARS outbreak in 2003 to guide public health reforms, which included the creation of new agencies such as the Public Health Agency of Canada and Public Health Ontario (Government of Canada 2004; Ontario Ministry of Health 2004). While progress has been made, COVID-19 has illuminated previously identified system deficiencies from these past reports relating to funding, organization, capacity (including surge capacity, and the training and distribution of public health personnel), and multi-jurisdictional and intersectoral collaboration.

First, the public health system remains inadequately funded. In 2003, public health accounted for $1.8-2.5 \%$ of total health expenditures, and 2.6-3.5\% of public expenditures (Government of Canada 2004). Despite increases in health care spending since that time, public health investments today account for roughly $2-8 \%$ of total expenditures. Estimates vary depending on the jurisdiction and method of reporting (i.e., what prevention and promotion services are included in the definition of public health) but remain crude (Canadian Institute for Health Information n.d.).

Second, the 2003 Naylor Report recommended that linkages between academic institutions and public health agencies require further strengthening through "co-location, joint venture research institutes, cross-appointments, joint recruitment, interchange, networks and collaborative research activities" (Government of Canada 2004). Since 2003, an important accomplishment has been the development of public health training initiatives. From the mid-2000s to present day, there has been a marked increase in the number of Bachelor and Masters of Public Health (MPH) programs, a re-emergence of Schools of Public Health, and increased investments in applied public health research. For example, the Canadian Institutes of Health Research-Public Health Agency of Canada (CIHR-PHAC) Applied Public Health Chairs Program was introduced and aimed to strengthen linkages between research and practice. PHAC also provided continuing education through its Skills Online Courses, although suddenly discontinued this training in 2017. Core public health competencies developed in 2007 provided the basic building blocks for public health education and professional development programs (PHAC 2008). They are guiding the recruitment, development and retention of the public health workforce but have not been updated in thirteen years. If these competencies are to form the basis of public health education and practice moving forward, they must be revised to reflect current and future public health challenges. For instance, the Council for Education in Public Health (CEPH) has recognized health equity as a foundational public health competency (CEPH 2016). Competency gaps already identified by schools and programs and professionals in public health, and other organizations also include the lack of attention to health, social and racial equity, competencies in Indigenous health, ecological determinants, and leadership (Parkes et al. 2020; National Collaborating Centre for Determinants of Health 2012). Overall, the advancements to date do not adequately address the Naylor Report's recommendations for strengthening the funding and capacity of the public health system and for integrated public health system-academic collaborations.

\section{Call to action}

We echo other COVID-19-related calls - such as the open letter by US health care workers to launch a permanent public health jobs corps (Health Community 2020), and the statement of the Association of Schools of Public Health in the European Region (Middleton et al. 2020), which requests long-term reinvestment in public health education and training from all levels of government - and recommend the following actions:

(1) Improve collaboration between public health education programs and public health agencies to address system needs such as surge capacity and persisting health inequities. By building on existing relationships, academic institutions can better respond to the needs of public health agencies in real-time. This can be accomplished through training the next cadre of public health professionals in all areas of public health, and through collaborative research to build the much-needed evidence base for effective and equitable public health practice. These activities will have the spillover benefit of increasing graduate job readiness and thereby quickly enhancing public health capacity.

(2) Fund a pan-Canadian public health training initiative that engages schools/programs of public health. Based on a renewed set of public health competencies, this initiative will encourage public health agency-academic collaborations in graduate training and continuing education. Topics 
could include equity-oriented leadership and collaboration skills to support intersectoral action aligned with a Health in All Policies approach (Tonelli et al. 2020), and system capacity requirements (e.g., surge capacity, contact tracing). Potential funders include PHAC and CIHR.

(3) Prepare a cadre of certified public health leaders who can progress along public health career pathways, including those already in practice. This certification program could be developed by the consortium of institutions leading a pan-Canadian training initiative (see call to action \#2). Effective public health leadership requires a unique and diversified skill set to work across sectors, better respond to future public health crises, and proactively develop equitable and sustainable communities.

The Network of Schools and Programs of Population and Public Health (NSPPPH), Canada's first network linking institutions that educate and train population and public health professionals for research, policy and practice roles, is well positioned to support these actions, identify collective training needs, and work with other system actors, including the six National Collaborating Centres for Public Health, the three provincial public health agencies, the Public Health Agency of Canada, and the Canadian Public Health Association, while building on existing university-based and practice-based capacity development initiatives. Canada needs to reinvest in its public health system now to be better prepared for future outbreaks and other competing public health issues, including the ongoing opioid crisis, noncommunicable diseases, food insecurity, climate change, and persisting inequities. We need to seize the COVID19 response as an opportunity to renew support for public health education and training, rebuild and strengthen public health capacity and infrastructure, and enhance intersectoral collaboration to address the social and environmental determinants of health equity. When governments are concerned about building sustainable public health systems, support for public health education also needs to be central. Robust systems must include strong linkages to the knowledge generation and education enterprise for creating a pipeline of relevant research, a cadre of high-quality public health professionals, and ongoing continuing education for practitioners and policy makers. Our actions now will determine whether we succeed in improving health and health equity across Canada in the coming years.

Acknowledgements The authors would like to acknowledge the editorial assistance of Alexandria Vincent.

\section{Compliance with ethical standards}

Conflict of interest The authors declare that they have no conflicts of interest.

\section{References}

Canadian Centre for Policy Alternatives. (2020). Alternative Federal Budget Recovery Plan. https://www.policyalternatives.ca/ publications/reports/alternative-federal-budget-recovery-plan. Accessed 10 Aug 2020.

Canadian Institute for Health Information. (n.d.). Health spending. https://www.cihi.ca/en/health-spending. Accessed 10 Aug 2020.

Council on Education for Public Health. (2016). Accreditation Criteria: Foundational Competencies. https://medicine.wright.edu/sites/ medicine.wright.edu/files/page/attachments/CEPH\%202016\% 20Foundational\%20Competencies.pdf. Accessed 10 Aug 2020.

Government of Canada. (2004). Learning from SARS: renewal of public health in Canada - report of the National Advisory Committee on SARS and Public Health. https://www.canada.ca/en/public-health/ services/reports-publications/learning-sars-renewal-public-healthcanada.html. Accessed 10 Aug 2020.

Guyon, A., \& Perreault, R. (2016). Public health systems under attack in Canada: Evidence on public health system performance challenges arbitrary reform. Canadian Journal of Public Health, 107, e326e329. https://doi.org/10.17269/CJPH.107.5273.

Health Community. (2020). Health community recommendations to strengthen the Biden plan to combat COVID-19 and prepare for future global health threats. https://docs.google.com/document/d/ 1TLi493HczC190E-eRW7EzIG9fvQCnV-rGKLULPDDlc4/edit. Accessed 10 Aug 2020.

Kouddous, S. A. (2020). Mike Davis on pandemics, super-capitalism and the struggles of tomorrow. https://madamasr.com/en/2020/03/30/ feature/politics/mike-davis-on-pandemics-super-capitalism-andthe-struggles-of-tomorrow/. Accessed 10 Aug 2020.

Mein S. A. (2020). COVID-19 and health disparities: the reality of "the Great Equalizer". Journal of General Internal Medicine, 1-2. Advance online publication. https://doi.org/10.1007/s11606-02005880-5.

Middleton, J., Martin-Moreno, J. M., Barros, H., Chambaud, L., \& Signorelli, C. (2020). ASPHER statement on the novel coronavirus disease (COVID-19) outbreak emergency. International Journal of Public Health, 65(3), 237-238. https://doi.org/10.1007/s00038020-01362-x.

Mishra, S., Kwong, J. C., Chan, A. K., \& Baral, S. D. (2020). Understanding heterogeneity to inform the public health response to COVID-19 in Canada. Can Med Assoc J, 192(25), e684-e685. https://doi.org/10.1503/cmaj.201112.

Santé Montréal. (2020). Inégaux face à la pandémie : populations racisées et la COVID-19.https://santemontreal.qc.ca/fileadmin/ fichiers/Campagnes/coronavirus/situation-montreal/point-sante/ populations-racisees/Populations-Racisees-Covid-19.pdf. Accessed 10 Aug 2020.

National Collaborating Centre for Determinants of Health. (2012). Core competencies for public health in Canada: an assessment and comparison of determinants of health content. Antigonish: Author, St. Francis Xavier University.

Ontario Ministry of Health. (2004). A plan of action: final report of the Ontario Expert Panel on SARS and Infectious Disease Control. http://www.health.gov.on.ca/en/common/ministry/publications/ reports/walker04/walker04_2.aspx. Accessed 10 Aug 2020.

Parkes, M., Poland, B., Allison, S., Cole, D., Culbert, I., et al. (2020). Preparing for the future of public health: ecological determinants of health and the call for an eco-social approach to public health education. Canadian Journal of Public Health, 111(1), 60-64.

Public Health Agency of Canada. (2008). Core competencies for public health in Canada. https://www.phac-aspc.gc.ca/php-psp/ccph-cesp/ pdfs/cc-manual-eng090407.pdf. Accessed 10 Aug 2020. 
The Institute for Gender and the Economy (GATE) and YWCA Canada. (2020). A feminist economic recovery plan for Canada. https:// www.feministrecovery.ca/. Accessed 27 Sept 2020.

Timothy, R. K. (2020). Coronavirus is not the great equalizer-race matters. The Conversation. https://theconversation.com/ coronavirus-is-not-the-great-equalizer-race-matters- 133867. Accessed 10 Aug 2020.
Tonelli, M., Tang, K.-C., \& Forest, P.-G. (2020). Canada needs a "Health in All Policies" action plan now. Can Med Assoc J, 192, e61-e67. https://doi.org/10.1503/cmaj.190517.

Publisher's note Springer Nature remains neutral with regard to jurisdictional claims in published maps and institutional affiliations. 